\title{
Radioecological Assessment of the Uranium Tailings in Tuyuk-Suu (Kyrgyzstan)
}

Djenbaev Bekmamat, Zholbolduev Baktiar, Zhumaliev Talant and Voitsekhovitch Oleg

Institute Biology \& Pedology of National Academy of Sciences Kyrgyz Republic, City Bishkek 265, Ave. Chui 720071, Kyrgyz Republic

\begin{abstract}
Radioecological Assessment of the Uranium Tailings in Tuyuk-Suu (Kyrgyzstan). The aim of our research is the radioecological assessment of the current state of uranium tailings in Tuyuk-Suu. The methods of field and laboratory analysis were conducted with the modern radiological and nuclear physics equipment. Gamma survey was shown that the surface of the tailings Tuyuk-Suu and Taldy-Bulak may effectively reduce the exposure dose of gamma radiation, the body Tuyuk Suu is flooding with water flowing near the river in a concrete channel, so it should be constantly monitoring the state of the tailings and the river Tuyuk-Suu. In this article is given the analysis and estimates of the current radiation condition of the tailings dam and Min-Kush settlement. It was for the first time made the radiological analysis after closing of the uranium tailings in a body of the most tail material and it is estimated states possible pollution to environment.
\end{abstract}

Key words: Uranium tailings, technogenic, radiobiogeochemistry, homogenized, inter-calibrations lab.

\section{Introduction}

Many dams of uranium tailings are located in the occupied areas, in zones seismically dangerous and subject to risk of a descent of landslides in the republic. Radiological impact on the environment and the population is not completely known - the low standard of living of the population and social problems, etc. contribute to the generally poor social and psychological situation in these technogenic areas, including threats and risks from radiation, and also other potential physical risks. Now in the territory of our republic there are a large number of radioactive sources (about 1,200). After the collapse of the USSR (Socialist Soviet Union Republics) in Kyrgyzstan, in an govern less state there were 55 dams of the uranium in the area of 770 hectares in which more than 132 million $\mathrm{m}^{3}$ of tails and 85 mountain dumps are stored. Waste, of $700 \mathrm{~m}^{3}$, occupies the space over 1,500 hectares, including 31 tailings dams and 25

Corresponding author: Bekmamat M. Djenbaev, professor, Dr., research fields: geosciences, bioreochemistry and coordinator. E-mail: bekmamat2002@mail.ru. dumps - waste of uranium production, of 5,183 million $\mathrm{m}^{3}$. As of 2010 their total radioactivity exceeds 90 thousand curries [1-4].

A preliminary analysis of the available literature $[2$, 4] data and assessments of current radiological conditions in the region of Min-Kush, there were identified the need to expand the exploring, which will create a conceptual model of the impact of the area with uranium legacy on the environment as a basis for further development of rehabilitation strategies.

\section{Material and Methods}

There were conducted the assignment of the IAEA (International Atomic Energy Agency) expert together with local experts to assess the current status and taking gamma dosimeters at the territory of tailings and their areas of influence. At the same time, it was measured the portable gamma dosimeters for mapping of radioactively contaminated areas. During the preparatory period, plans were developed radiometric survey together with the staff of the IAEA Seibersdorf analytical laboratory and BPI (Biology \&Pedology Institute) National Academy of Sciences, and samples 
were taken for laboratory analysis of the soils of tailings on the horizon $[2,5,6]$.

There were conducted a comprehensive survey of the investigated territory, according to the methodology and radiobiogeochemistry research of various taxons of the biosphere. For conducting a radiometric survey were used the following tools (as well as the associated GPS devices and data acquisition system):

- Pico Envirotec Model PGIS-21 a portable gamma spectrometer with the scintillation (NaI) detector and system of data processing on the basis of Android.

- Pico Envirotec portable systems for measurement of an equivalent dose of gamma irradiation on the basis of the counter of energy of Geyger Müller covering a wide range of measurements from $50 \mathrm{nSv} / \mathrm{h}$ to 400 $\mathrm{mSv} / \mathrm{h}$ GEDR.

- Thermoluminescent scale the RadEye radiometer of the B-20 model of a universal purpose with GM's (Geygera-Müller) counter.

- The thermoluminescent portable analyzer which can be connected with the external GPS device and allows to define presence the trasser of concentration of some metals and other toxic elements, including uranium in soils and ground deposits.

- Measurements were taken on semiconductor detectors gamma spectrometer GX4019 with the software of Genie-2000 S502, S501 RUS. Working range of energy of the detector is $50 \mathrm{kev}$ to $3 \mathrm{Mev}$.

Measurements were taken on semiconductor detectors gamma spectrometer GX4019 with the software of Genie-2000 S502, S501 RUS. Working range of energy of the detector is $50 \mathrm{kev}$ to $3 \mathrm{Mev}$.

In most places, the depth of the surface of the tailings and the surface material are ranged from 0.3 to $0.5 \mathrm{~m}$., from the surface of the coating. Uranium tailings production residues mixed with sand and ash material and they were placed in the river valley Tuyuk-Suu, about 4-6 $\mathrm{m}$ at the sides of the tailings to $12-14 \mathrm{~m}$ of the central part of the soils of the tailings. The upper part of the tailings is almost completely flooded. In some areas of the tailing edge of the upstream sector of the river tail material could not be taken away already at a depth of about $3 \mathrm{~m}$, since the core is immersed in liquid pulp. In some areas of the central part, soft and liquid slurry was detected at a depth of about $9 \mathrm{~m}$ from the surface of the coating (Fig. 1).

The water saturation of the tailings material is not allowed to extract material from the wells by auger and core drilling at depths below the upper edge of the caudal zone of complete saturation of the material with water. Therefore, the sampling of the soil material was failed by only four wells to a depth of 7-9 $\mathrm{m}$. From two wells were selected cores from the surface layers of the body of the tailings to a depth of 3-4 m. In addition, samples were taken from pits that have been made in some areas to depths of 1.5-2 m. Pits were laid in those areas where manual drilling was impossible to perform a deeper, as cores rested on metal construction and demolition waste, which was brought here after the dismantling of the former hydrometallurgical plant.

The total depth of wells drilled was approximately 60 linear meters, which corresponds to the planned volume of drilling operations. Samples were taken every $0.5 \mathrm{~m}$ of core. Procedure of sampling is shown in Fig. 2.

First the samples from the depth of selection were spread on the surface and they were covered with plastic wrap. Then it was done the gamma logging survey. In wells was down the detector on the cable connecting with the analyzer radiometer, count of the external gamma radiation in the well was read every $0.5 \mathrm{~m}$. In the layers, where the observed elevated levels of radioactivity, all samples are sorted for further analysis. In layers that housed the gangue material samples were selected by the tail rarer grid. This combination of gamma-logging surveys and sampling of the wells allows you to optimize the number of samples taken and analyzed, the vertical structure of the distribution of the most polluted and relatively clean soil layers in the body of the tailings. After the measurement, the wells were covered with excavated 

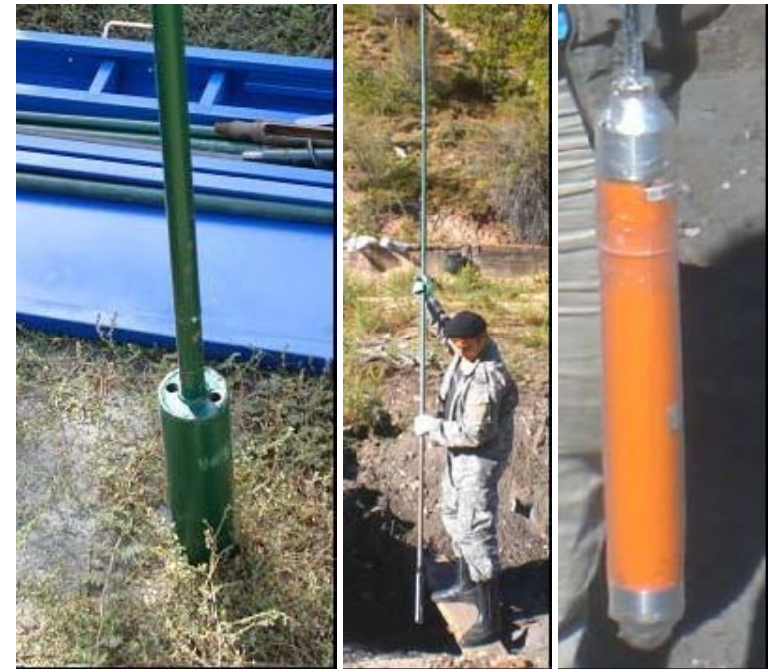

Fig. 1 Hand drills and gamma logging tool used for drilling and testing of wells.
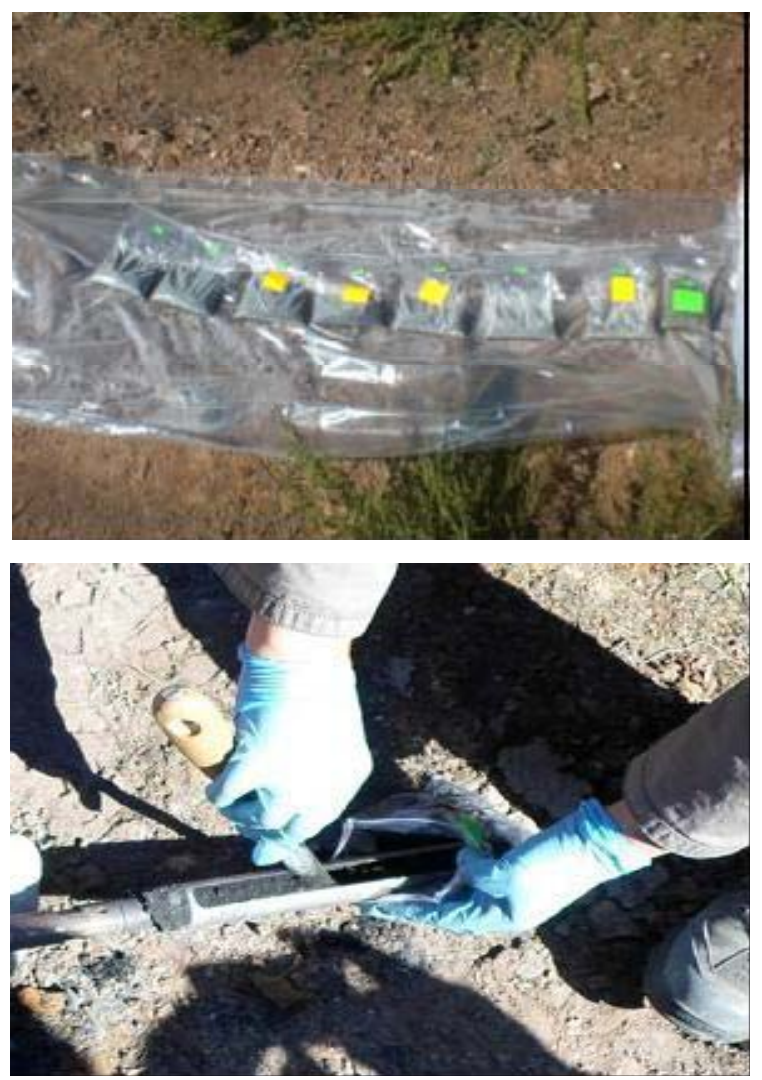

Fig. 2 Sampling procedure from a well in a tailings dam surface.

earth and covered with clean soil. Assess the level of gamma dose rate at the surface of the topsoil showed that the level of gamma dose does not exceed the average values of the background radiation on the surface of the tailings.
The selected material allowed us to analyze the gamma spectrometry and make important preliminary findings, which are discussed below. A total of 70 samples selected caudal material and coating material. From each well was also selected for at least 3-4 standard samples (a total of 16 samples). They were thoroughly homogenized and divided into three control samples for independent determination of the activity of ${ }^{238} \mathrm{U},{ }^{226} \mathrm{Ra}$ and ${ }^{210} \mathrm{~Pb}$ in different laboratories that have been selected to provide analytical measurements: Radiometric Laboratory of Biology and Pedology Institute of National Academy of Sciences of the Kyrgyz Republic, the IAEA laboratories in Seibersdorf and Radiochemistry Laboratory Spectrometry Division Environmental Radiation Monitoring Ukrainian Hydrometeorological Institute, whose experts also participated in the sampling and preparation of the test samples for analytical measurements. Environmental samples (water, sediments, soil and plant samples) were selected from the territory of the tailings Tuyuk-Suu and adjacent residential areas of the region Min-Kush.

Water samples were selected for all laboratories participating in the program, which also allow comparison of results of the determination of radionuclide in the water by different laboratories. Water samples were collected in plastic containers or plastic bottles. Preservation samples were carried out by adding water to the selected container $10 \mathrm{~mL}$ of nitric acid. The samples were taken in the river of the Tuyuk-Suu above the tailing, below the tailing, from the underground and the downstream to the village Ming-Kush.

In the territory of the mine \#21 was also sampled sediment, which was formed from the flow of mine water. Sedimentary material was analyzed for a wide range of contaminants in the analytical laboratory of the IAEA Seibersdorf. Bottom sediment samples were also selected above and downstream river of the Tuyuk-Suu (the tailing). Comprehensive analysis of precipitation data allowed us to estimate the degree of 
influence of leakage from the tailings seepage water that is saturated with water, through a gallery in the waters of the river.

Water samples (10-liter) from the river were also selected and delivered to the laboratory of Biology and Pedology Institute National Academy of Sciences. Integrated water sample was divided into three parts and delivered to other laboratories of the Kyrgyz Republic. The same samples were analyzed in the laboratory of the IAEA Seibersdorf Laboratory and Ukrainian Hydrometeorological Institute (Ukr NIGMI) [5-7].

\section{Results of Researches}

\subsection{Tailing's Material}

Generally structure of the tailings dam are the sheeting $-0.6 \mathrm{~m}$ (stony soil) is up to one depth of $2.0 \mathrm{~m}$
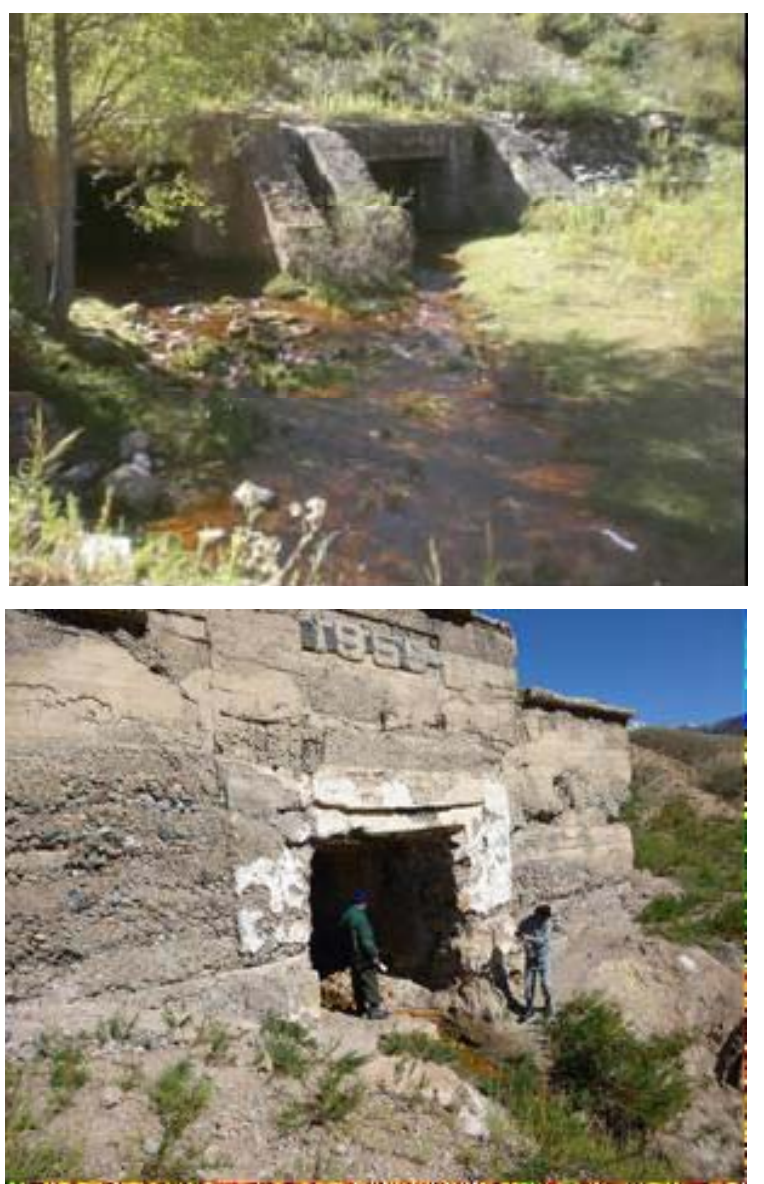

Fig. 3 The sampling water from the river Tuyuk-Suu was in the territory of the tailing. lower construction garbage, small metal fragments and concrete. Lower than $2 \mathrm{~m}$ the material of tails is rather uniform up to the depth of $9 \mathrm{~m}$ is located. Below $9 \mathrm{~m}$ the layer soft, plastic and a liquid pulp is located. Tests are selected up to the depth of $9 \mathrm{~m}$ and below generally liquid consistence.

The scale of radiation and results of determination of specific activity of ${ }^{238} \mathrm{U},{ }^{226} \mathrm{Ra}$ and ${ }^{210} \mathrm{~Pb}$ in tests of tail material allow establishing vertical profiles of power of an exposition dose that for layers saturation zones are higher levels of pollution of a pulp in a body of the tailings dam are not very uniform. It creates difficulties in an assessment of the general maintenance of radioactive waste in a tailings dam body. Specific activities of ${ }^{238} \mathrm{U}$ in the tailing's material are rather low, changing from $0.2-1.0 \mathrm{~Bq} / \mathrm{g}$ to $2-4 \mathrm{~Bq} / \mathrm{g}$. Activities of ${ }^{226} \mathrm{Ra}$ and ${ }^{210} \mathrm{~Pb}$, on tailings dam layers well correlate with vertical distribution of ${ }^{238} \mathrm{U}$. However, it is practically in balance among themselves and their activities of the radionuclide changes in the range from 5 to $20-30 \mathrm{~Bq} / \mathrm{g}$. The most polluted layer of tailing's material extends at depths of 5-7 $\mathrm{m}$ from a sheeting surface. Values the scale of a dose in a body of the tailings dam corresponds to a layer-by-layer arrangement of rather pure layers of tail material (with the low maintenance of ${ }^{226} \mathrm{Ra}$ and MED 1-5 $\mu \mathrm{Sv} / \mathrm{h}$ ) to layers with the raised content of ${ }^{226} \mathrm{Ra}$ with MED (power of an exposition dose) $16 \mu \mathrm{Sv} / \mathrm{h}$ and more (Fig. 4).

In all these laboratories different types of highly effective semiconductor Germanic detectors for the analysis of ranges scale of the radiating radionuclide in tailing materials and tests of environment were used. Also methods of alpha spectrometry and liquid scintillation counters were used. Tests from the tailings dam were located in aluminum containers (the volume of $40 \mathrm{ml}, 40-50$ aliquot) or containers from plexiglas of high density in which they were stored within 30 days for achievement of balance between radionuclide of radium and radon. Values of mass activity is ${ }^{238} \mathrm{U}$ (were determined in a power range by activity scale of the line of products of disintegration $234 \mathrm{Th}$ or $234 \mathrm{mPa}$ ). 


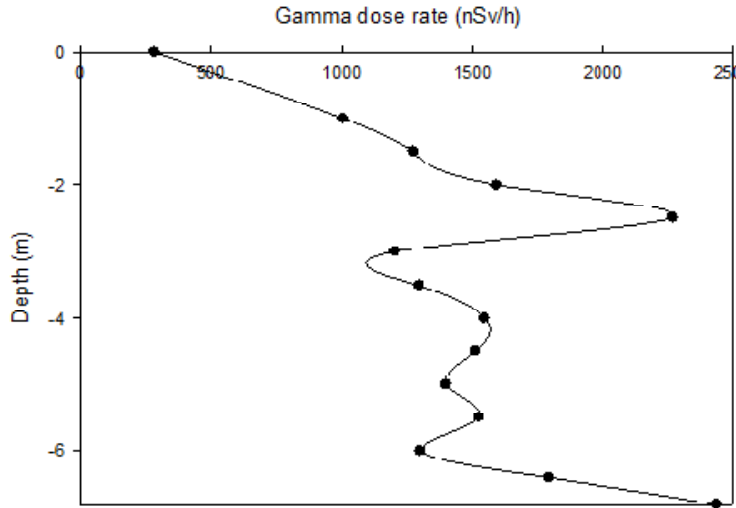

(a)

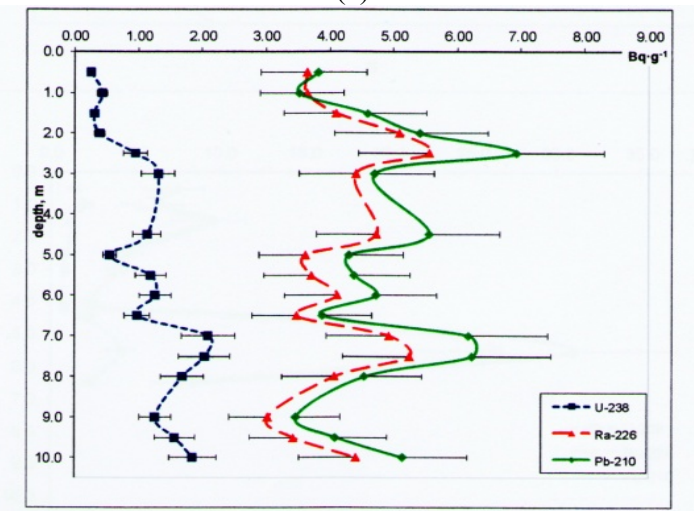

(b)

Fig. 4 The Well No. 6. a profile on depth scale of a dose (a) and vertical distribution of specific activity in the tailings dam Tuyuk-Suu (b).

Determination of activity ${ }^{226} \mathrm{Ra}$ was carried out also on a range scale of lines of products of its disintegration $\left({ }^{214} \mathrm{~Pb},{ }^{214} \mathrm{Bi}\right)$ and ${ }^{210} \mathrm{~Pb}$ taking into account adjustments. Values of activity ${ }^{238} \mathrm{U},{ }^{234} \mathrm{U},{ }^{230} \mathrm{U}$, ${ }^{210} \mathrm{Po}$ and ${ }^{226} \mathrm{Ra}$ in some control tests were defined with the help of a spectrometry alpha by method of isotope dilution, and activity ${ }^{210} \mathrm{~Pb}$ by method of a liquid scintillation in a sample that is far from $0.5 \mathrm{~g}$ who was selected from control test. Results of measurements in each of laboratories are given in the report and discussed further.

Tests of water were analyzed in two laboratories with use of methods of alpha radiometry and a liquid scintillation. The content of micro impurity in four samples was defined with use by method of mass of spectrometry of ICP-MS. The chemical ionic composition in tests of water was carried out by standard photometric methods.
Testing was held to achieve comparability of results which were received in different laboratories and different methods. To estimate comparability of results of different laboratories of five tests of tail material were carefully homogenized, divided into three equal parts and are sent for determination of activity of radionuclide to them in three laboratories which took part in analytical works with the tests which are selected during the investigation. Besides 11 tests of soil were homogenized and distributed between laboratories of UKR NIGMI and the Kyrgyz KR NASN BPI laboratory for boundaries-laboratory checking of analytical results which were supposed to be received with use of the same methods and for the same type of gamma and spectrometer detectors which were possessed by these laboratories. It allowed then to take mass measurement of tests by methods scale of spectrometry in the laboratory of biology and pedology of institute to minimize transportation of a large number of tests of soil out of borders of Kyrgyzstan. In addition five control samples of soil from the same series were also analyzed in IAEA laboratories (in Seibersdorf) for the purpose of definition in tests ${ }^{238} \mathrm{U}$ and ${ }^{226} \mathrm{Ra}$, methods scale and an alpha of spectrometry. Thus, inter-calibrations of results of measurements of three main laboratories participating in this work that allowed them to correct all results of measurements were carried out and to carry out the full mass analysis of tests, using the different analytical methods available in laboratories. The average values of results of measurements received with use of different analytical methods for the same test allowed to define true statistically reliable results of measurements and to accept them as reference values on which measurements private results in laboratories participants of the project were calibrated.

The results received by various methods with a certain reliability of measurements, it allowed to estimate the general uncertainty of values of activity which in general was accepted between 10 and $15 \%$. Results of determination of activity was ${ }^{238} \mathrm{U},{ }^{226} \mathrm{Ra}$ and 
Table 1 Determination of activity of $U$ in the tests of the tailings dam, measured by means of methods scale, alpha spectrometry and ICP-MS (Bq/kg).

\begin{tabular}{lllll}
\hline & Gamma spectrometry & ICP-MS & Alfa-spectrometry & Alfa-spectrometry \\
\hline Sample & ${ }^{238} \mathrm{U}$ & ${ }^{238} \mathrm{U}$ & ${ }^{238} \mathrm{U}$ & ${ }^{234} \mathrm{U}$ \\
$\mathrm{S} 02$ & $1,123 \pm 43$ & $862 \pm 16$ & - & - \\
$\mathrm{S} 03$ & $1,461 \pm 22$ & $1,630 \pm 13$ & $1,442 \pm 31$ & $1,628 \pm 34$ \\
$\mathrm{~S} 04$ & $1,524 \pm 43$ & $1,508 \pm 14$ & - & - \\
$\mathrm{S} 05$ & $2,570 \pm 75$ & $2,482 \pm 14$ & $3,162 \pm 64$ & $3,360 \pm 68$ \\
\hline
\end{tabular}

Table 2 Determination of activity ${ }^{226} \mathrm{Ra}$ in the tests of the tailings dam, measured by means of gamma and alpha spectrometry (Bq/kg, dry weight).

\begin{tabular}{lll}
\hline Sample & Alfa-spectrometer & Gamma-spectrometer \\
\hline S02 & $4,786 \pm 98$ & $4,730 \pm 20$ \\
S03 & $5,854 \pm 112$ & - \\
S04 & $7,892 \pm 142$ & $7,237 \pm 44$ \\
S05 & $10,240 \pm 183$ & $10,844 \pm 22$ \\
\hline
\end{tabular}

Table 3 Results of definition of characteristics of radioactive pollution of the tests of water which are selected in the region of Ming-Kush.

\begin{tabular}{|c|c|c|c|c|c|c|c|c|c|}
\hline № & Sampling place & Grossalpha & Crossbeta & ${ }^{238} \mathrm{U}$ & ${ }^{234} \mathrm{U}$ & ${ }^{226} \mathrm{Ra}$ & ${ }^{210} \mathrm{~Pb}$ & ${ }^{210} \mathrm{Po}$ & $\begin{array}{l}\mathrm{pH} \\
\mathrm{Eh}\end{array}$ \\
\hline & L-1 & & $\mathrm{Bq} \mathrm{L}-1$ & Bq L-1 & $\mathrm{Bq} \mathrm{L}-1$ & $\mathrm{~Bq} \mathrm{~L}-1$ & $\mathrm{~Bq} \mathrm{~L}-1$ & $\mathrm{~Bq} \mathrm{~L}-1$ & \\
\hline 1 & $\begin{array}{l}\text { R. Tuyuk-Suu higher on } \\
\text { a watercourse of tailings } \\
\text { dams }\end{array}$ & $0.25 \pm 0.07$ & $0.32 \pm 0.10$ & $0.03 \pm 0.006$ & $0.04 \pm 0.008$ & $0.06 \pm 0.02$ & $0.05 \pm 0.01$ & $0.01 \pm 0.003$ & $\begin{array}{l}7.89 \\
1.54\end{array}$ \\
\hline 1 & $\begin{array}{l}\text { R. Tuyuk-Suu higher on } \\
\text { a watercourse of tailings } \\
\text { dams, copy }\end{array}$ & $0.22 \pm 0.07$ & $0.36 \pm 0.11$ & $0.03 \pm 0.006$ & $0.03 \pm 0.008$ & $\begin{array}{l}0.06 \pm \\
0.02\end{array}$ & - & - & - \\
\hline 2 & $\begin{array}{l}\text { Vytok from gallery in } \\
\text { the river of Tuyuk-Suu is } \\
\text { lower than hv-storage }\end{array}$ & $0.85 \pm 0.26$ & $1.47 \pm 0.44$ & $0.30 \pm 0.06$ & $0.32 \pm 0.06$ & $0.08 \pm 0.03$ & $0.28 \pm 0.09$ & $0.04 \pm 0.01$ & $\begin{array}{l}7.31 \\
1.35\end{array}$ \\
\hline 3 & $\begin{array}{l}\text { the river Tuyuk Suu is } \\
\text { lower on a current } \\
\text { hv-storages }\end{array}$ & $0.38 \pm 0.11$ & $0.74 \pm 0.22$ & $0.12 \pm 0.025$ & $0.25 \pm 0.05$ & $0.03 \pm 0.01$ & $\begin{array}{l}7.70 \pm \\
1.55-\end{array}$ & - & - \\
\hline 4 & $\begin{array}{l}\text { the river Tuyuk Suu is } \\
\text { lower on a current } \\
\text { region of Ming-Kush }\end{array}$ & $0.36 \pm 0.11$ & $0.36 \pm 0.11$ & $0.13 \pm 0.025$ & $0.23 \pm 0.05$ & $0.05 \pm 0.01$ & $0.05 \pm 0.01$ & $\begin{array}{l}0.003 \\
\pm 0.003\end{array}$ & - \\
\hline 5 & $\begin{array}{l}\text { Ming-Kush, water from } \\
\text { mine No. } 17\end{array}$ & $3.45 \pm 1.04$ & $6.70 \pm 2.00$ & $1.70 \pm 0.26$ & $1.70 \pm 0.26$ & $0.21 \pm 0.06$ & $\begin{array}{l}7.39 \\
2.45\end{array}$ & - & - \\
\hline 6 & $\begin{array}{l}\text { Ming-Kush, water from } \\
\text { mine No. } 21\end{array}$ & $2.53 \pm 0.75$ & $5.92 \pm 1.77$ & $0.60 \pm 0.12$ & $0.60 \pm 0.12$ & $0.35 \pm 0.10$ & $0.03 \pm 0.01$ & $\begin{array}{l}0.006 \\
\pm 0.003\end{array}$ & $\begin{array}{l}6.39 \\
0.34\end{array}$ \\
\hline 7 & $\begin{array}{l}\text { Drinking water } \\
\text { in the Ming-Kush }\end{array}$ & - & - & - & $0.13 \pm 0.01$ & $0.19 \pm 0.005$ & $0.01 \pm 0.002$ & $0.06 \pm 0.01$ & - \\
\hline 8 & $\begin{array}{l}\text { Drinking water in center } \\
\text { Seibersdorf }\end{array}$ & - & - & - & $0.07 \pm$ & $\begin{array}{l}0.09 \pm \\
0.003\end{array}$ & - & - & $\begin{array}{l}7.39 \\
0.28\end{array}$ \\
\hline
\end{tabular}

${ }^{210} \mathrm{~Pb}$ in tailing materials of IAEA laboratory, it is given in Tables 1 and 2 .

\subsection{Water Pollution}

Results of the analysis of radionuclide in the tests of water from the river Tuyuk-Suu and mine waters in Ming-Kush are presented in Table 3.

The analysis of the data in Table 3 allows us to conclude that the current infiltration of water from the tailings, coming into the underground, show the uranium concentration increase approximately three times high in the river of water below the tailings. In terms of total alpha activity is observed increase of about 1.5 times. However, according to the data on the pollution of ${ }^{226} \mathrm{Ra}$ in water samples above and below the location of the tailings along the river, to establish a 
significant influence infiltration of water from the body of the tailings to the river water pollution significantly failed. Activity of ${ }^{226} \mathrm{Ra}$ in the water of the river and the water come from the underground and they have similar levels of pollution.

A large amount of iron, which is washed out of the body of the tailings, which can be seen and reddish water in the drainage gallery, indicates good redox conditions in the body of the tailings $(\mathrm{pH} 7.3)$ is sufficient for good fixation ${ }^{226} \mathrm{Ra}$ in the matrix material and the tail insufficient to significant leaching of uranium from the remainder of the tailings pore water. More informed conclusions can be made only on the basis of the analysis of the results of systematic observations seasonally within the site-monitoring program, as well as the results of the study of the physicochemical properties of uranium and radium in the body of the tailings.

Despite of the relative increase in the uranium concentration in the waters of the river, which located downstream of the tailings, its concentration in the river is low at $0.1-0.2 \mathrm{~Bq} / \mathrm{L}$, which corresponds to the variability within the normal natural background. For comparison of the concentration of uranium in drinking water in Seibersdorf (Austria) is $0.07 \mathrm{~Bq} / \mathrm{L}$, and in many rivers in the Nordic countries is up to $1 \mathrm{~Bq}$ per

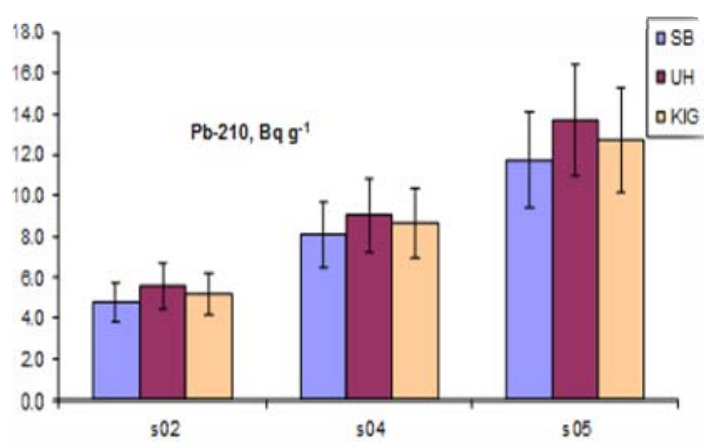

Fig. 5 Comparison of the results of the analysis in various laboratories for the purpose of testing of the received values of activity ${ }^{238} \mathrm{U},{ }^{226} \mathrm{Ra}$ and ${ }^{210} \mathrm{~Pb}$ showed also good comparability of the analytical data, it obtained in partner laboratories from Kyrgyzstan (KIG), UKRNIGMI (UH) and IAEA (SB) which used scale spectrometer detectors for this research (For example, Fig. 5). liter or more. For comparison, the standard for the maintenance of ${ }^{238} \mathrm{U}$ in the drainage water discharged from uranium facilities in Germany-2 Bq/L. Standard security of the concentration of ${ }^{238} \mathrm{U}$ in drinking water $\mathrm{EU}$ is $0.5 \mathrm{~Bq} / \mathrm{L}$ [8-10].

The results of our measurements show the suitability of the water of the river Tuyuk-Suu for drinking. On the other hand for a more informed assessment of water pollution in the existing conditions need to continue research in different seasons. It is also important to analyze the possible effects of accidental flooding of the tailings in a landslide that in this area there is still a danger.

However, the data also show that the concentration of ${ }^{238} \mathrm{U}$ in the water shaft, which can be used for drinking, irrigation and watering cattle (mines and \#17 and \#21) exceeds EC safety standard and is significantly higher than in the river Tuyuk-Suu. However, the combined effect of mine water pollution of the river is not essential because the cost of water in these mines \#17 and \#21 estimated about 2-3 and 12-15 $\mathrm{L} / \mathrm{s}$, respectively, while the water flowing in the river Tuyuk-Suu changes during the years from 5 to $20 \mathrm{~m}^{3} / \mathrm{s}$.

However, it should continue to monitor and take measures to limit the consumption of mine water for drinking, irrigation and livestock watering gardens locals. Estimates of potential exposure of the local population through the use of mine water should also be included in the EIA (Environmental Impact Assessment).

\section{Conclusion}

Our study should be viewed as preliminary analyzes in the natural and technogenic province, it is assumed that these data can be supplemented by the results of monitoring, which are national and international partners. The data will be useful for radioecological dose assessment and verification of models that should be used to assess the radiological impacts of tailings on the environment and the exposure of the population in the existing conditions, as well as to assess the 
consequences of potential accidents and possible strategies for the implementation of rehabilitation, which will be considered in the future.

Gamma survey shows that there exists today a coating on Tuyuk-Suu tailings and Taldy-Bulak can effectively reduce the exposure dose of gamma radiation to the level of natural background. However, this should be monitored and the coatings do not damage the surface. It is recommended to protect the tailings and install warning signs that are not currently available. In some cases, the coating thickness of tailings is not sufficient, pits, which remained after the excavations showed that the thickness of the coating is only $30-40 \mathrm{~cm}$. Therefore, it is also necessary to conduct regular supervision of the state of the coating and, if necessary, implement corrective actions to restore coverage in places digs.

The current state of the tailings Tuyuk-Suu is relatively stable. Primer coating protects the environment from the separation of the tail material. The exposure rate levels of gamma irradiation on the surface of the tailings with the exception of some of its sites, which violated a protective coating remains close to the environmental background.

The main factors of radiation risks for the population of Ming-Kush is a high concentration of active ${ }^{222} \mathrm{Rn}$ and its decay products in the homes, as well as relatively high levels of external gamma radiation, the cause of which cannot be controlled by the use of a population of contaminated materials from the site area. It is recommended to conduct a comprehensive analysis and extensive gamma dosimeter survey all of Ming-Kush and farmsteads and houses, which is expected to resettle residents in case of elevated levels of radiation.

The data obtained suggest that the body is tailing Tuyuk-Suu flooding of water flowing near the river in a concrete way. The level of occurrence of water (to saturation) is from $7-8 \mathrm{~m}$ below the surface of the tailings in the central part, $10-11 \mathrm{~m}$ at the bottom and 3-4 $\mathrm{m}$ in its upper part. This means that a large part of the body submerged tailings caudal material is in liquid slurry.

In the central part of the tailings Tuyuk-Suu probably buried remains of dismantling; it was owned by former hydrometallurgical manufactory. Keep in mind that in the body of the tailings were disposed of most polluted parts of the equipment. At one of these fragments in the excavation of the tailings gamma radiation dose rate reached $10 \mu \mathrm{Sv} / \mathrm{h}$ or more.

The concentration of uranium in the material of the tailings is low and varies in most samples taken in the range of $0.5-2.5 \mathrm{~Bq} / \mathrm{g}$. Activity of ${ }^{226} \mathrm{Ra},{ }^{210} \mathrm{~Pb},{ }^{230} \mathrm{Th}$ in the material is almost in equilibrium with each other, their activity varies widely distributed. The maximum activity levels are located at depths close to the surface of complete saturation. The most polluted material caudal fibers were observed in the wells 7 and 9 in the central part of the tailings at depths of between 5 and 7 $\mathrm{m}$ from the surface of the coating. Regarding the distribution of synchronous activity of ${ }^{238} \mathrm{U}$ and ${ }^{226} \mathrm{Ra}$ at the tail of the body of material depth in all wells drilled indicates that the body of tailings absent any significant geochemical conditions for selective elution and leaching of ${ }^{238} \mathrm{U}$ in the tailings pulp pore solutions compared ${ }^{226} \mathrm{Ra}$. Geochemical conditions correspond to relatively neutral under which conditions cannot be observed for increased migration of uranium and radium in water filtration. This explains the fact that the high water body tailings transition of uranium and radium in water infiltration from it is low.

The analysis of water concentration on the ${ }^{238} \mathrm{U}$ from an underground part of the tailings indicates that pollution is about 10 times higher than in the river above the location of the tailings flow and drainage of the subterranean reservoir (gallery) leads to increase the uranium in water of the river Tuyuk-Suu four times (0.03 Bq/L to $0.13 \mathrm{~Bq} / \mathrm{L})$. Increasing of the activity of radium in the water of the river above and below location of the tailings was not noticed. In modern conditions the effect of tailings on the quality of drinking water of the river Tuyuk-Suu can be regarded 
as significant in relation to the standard of safety of drinking water (for example, in the $\mathrm{EU}$, which is 0.5 $\mathrm{Bq} / \mathrm{L}$ ). Tuyuk-Suu can be regarded as significant in relation to the standard of drinking water safety in the $\mathrm{EU}$, which is $0.5 \mathrm{~Bq} / \mathrm{L}$. The centralized water supply of the population of the settlement of Ming-Kush is organized only partially from mountain sources which are not connected with river Tuyuk-Suu. Nevertheless, the concentration of ${ }^{238} \mathrm{U}$ in such water was also defined at the level of $0.12 \mathrm{~Bq} / \mathrm{L}$ that is admissible. For the top part of the settlement, cases of use of mine waters for a watering place of cattle and watering were noted. The content of uranium and other natural radionuclide in water of the flooded mines No. 17 and No. 21 is rather high (to $2 \mathrm{~Bq} / \mathrm{L}$ ). Therefore, water use from these sources has to be limited and be controlled regulator.

Centralized water supply of the population in the region of Ming-Kush was organized only partially from mountain springs and it is not linked from the river Tuyuk-Suu. However, the concentration of ${ }^{238} \mathrm{U}$ in such kind of water was also determined to be 0.12 $\mathrm{Bq} / \mathrm{L}$, which is acceptable. For the upper part of the village, there were cases of using mine water for irrigation and livestock watering. The concentration of uranium and other natural radionuclide in water and submerged mines \#17 \#21 is sufficiently high (up to 2 $\mathrm{Bq} / \mathrm{L}$ ). Therefore, the use of water from these sources should be limited and monitored by the regulatory body.

According to the results of our survey, it can be assumed that the risks of radiation exposure, which are associated with the pollution of the river for the population living downstream Tuyuk-Suu taking stock of the area Tuyuk-Suu would not be significant. Planning of measures to bring uranium legacy facilities in the regions of Ming-Kush in a safe state should include consideration the strategy of stabilization (preservation) or other alternative long-term solutions to the problem Tuyuk-Suu tailings, as well as carrying out social planning for decontamination and arrangement of people, however, these estimates should be confirmed more thoroughly.

\section{References}

[1] Bykovchenko, U. G., Bykov, E. I., and Kydyrov, A. I. 2003. "Pollution of the Biosphere Technogeny Waste of Uranium in Kyrgyzstan." Science and New Technologies (3): 84-5.

[2] Djenbaev, B. M., and Mursaliev, A. M. 2012. Biogeochemistry of Natural and Technogenic Ecosystems of Kyrgyzstan. B.: Science.

[3] Djenbaev, B. M., Kaldybaev, B. K., and Zholboldiev, B. T. 2012. Radioactive Waste, edited by Dr. Abdel Rahman, R. O. InTech.

[4] Torgoyev, I. A., and Alyoshin, U. G. 2009. Geoecology and Waste of a Mining Complex of Kyrgyzstan. Bishkek: Science.

[5] Cusin, A. M. 1991. A Natural Radioactive Background and Its Value for the Biosphere of Earth. M.: Science.

[6] International Atomic Energy Agency. 2009. Quantification of Radionuclide Transfers in Terrestrial and Freshwater Environments for Radiological Assessments. IAEA-TECDOC-1616, Vienna: IAEA

[7] Djenbaev, B. M., Shamshiev, A. B., Jolboldiev, B. T., Kaldybaev, B. K., and Jalilova, A. A. 2008. The Biogeochemistry of Uranium in Natural-Technogeny Provinces of the Issik-Kul/Uranium, Mining and Hydrogeology. German, Freiberg: Technical University, 673-80.

[8] Minzdrav Rossii. 1999. Standards of Radiation Safety (NRB-99). Moscow: Minzdrav Rossii.

[9] International Atomic Energy Agency. 2003. Radiation Protection Against Radon in Workplaces other than Mines. Safety report series, IAEA, Vienna.

[10] International Commission on Radiological Protection. 1991. Recommendations of the International Commission on Radiological Protection, ICRP Publication 60. Ann. ICRP. 21. Ottawa: ICRP. 